\title{
AC 2008-2834: DEVELOPING ENGINEERING ETHICS ACROSS THE CURRICULUM BEST PRACTICES: THE EAC TOOLKIT
}

Jose Cruz, University of Puerto Rico-Mayaguez

William Frey, University of Puerto Rico-Mayaguez

Halley Sanchez, University of Puerto Rico-Mayaguez

Aury Curbelo, University of Puerto Rico-Mayaguez 


\section{Developing Engineering Ethics Across the Curriculum Best Practices: The EAC Toolkit}

Abstract - This paper will discuss a new project in ethics across the curriculum teaching and pedagogy, the EAC Toolkit. The Toolkit project, currently under funding by the National Science Foundation, is constructing an interactive online community where collaborators work to develop instructional materials designed to integrate ethics into the business, science, and engineering curriculum. This essay will characterize the Toolkit's components as they interact with the courseware provided by Connexions ${ }^{\circledR}$. It will also describe two EAC modules that have emerged in its initial stages of implementation. Finally, it will outline the activities, spell out the objectives, and summarize the assessment results of a series of interactive workshops held in the spring and fall of 2007.

\section{Background}

Because it allows BSE (business, science, and engineering) professors to serve as ethics mentors, ethics across the curriculum (EAC) has proven effective in integrating ethics into mainstream BSE curricula and in providing students with a practical ethics education. ${ }^{1}$ EAC, however, requires a robust educational infrastructure which empowers BSE professors as ethics mentors and provides them with renewable materials to carry out this role.

Modeled upon the practice of open source code development effectively used by computer programmers to collaborate in the development of software and building on an existing open courseware tool named Connexions ${ }^{\circledR 2,3,4,5}$, the project known as the EAC Toolkit has established an online environment that enables the sharing of best practices in ethics instruction. The Toolkit online platform facilitates integrated access, collaborative creation, continual improvement, and interactive dissemination of EAC resources and instructional best practices. It includes resources authored by and collaboratively developed through the EAC community. As members of the EAC community share the insights they have gained by using EAC resources, they have generated meta-knowledge (knowledge about the resources and their use) that the Toolkit collects, stores, and feeds back into its further development. The robust interactive element provided by the Toolkit adds value to online materials, textbooks, scholarly papers, ethics case studies, etc. Finally, because the Toolkit serves as a continuous, virtual workshop, it has begun to build an online community where engineering, science, business and ethics educators come together, interact, collaborate, and co-mentor. Updating, refining and expanding the Toolkit's EAC materials has become a self-sustaining process whereby the supporting EAC community is formed and solidified by the very Toolkit it sustains.

\section{EAC Toolkit Roles and Activities}

In designing the EAC Toolkit concept, its developers began with a series of levels representing different kinds and degrees of participant involvement. In its current phase, Toolkit developers have reshaped these levels and their correlative activities to fit the architecture of Connexions ${ }^{\circledR}$ courseware. This section will outline the level, enumerate its correlative activities, and identify the Connexions ${ }^{\circledR}$ courseware component upon which the level and its activities are built. 
- The guest or browser level provides a library of resources (cases, modules, and assessment instruments) that have been developed by EAC faculty. It also includes contextualized links to other resources available online. The objective is to emphasize and disseminate EAC resources in a practical, efficient and user-friendly fashion. Connexions ${ }^{\circledR}$ supports this level and its activities by means of its Content Commons, a space consisting of published modules accessible to the general public. The new lens feature allows different organizations (professional societies, business corporations, education accreditation societies) to endorse certain modules and draw these into collections recommended to members. ${ }^{6}$

- The member level builds upon the first level by adding feedback and registration capabilities. By participating in the EAC community through reviews, comments, and feedback, members help to assess, document, and disseminate EAC resources. Connexions ${ }^{\circledR}$ provides a number of features that support this level. Module authors' e-mail addresses are included at the end of each module to permit members and browsers to give authors feedback. Each module also offers a link entitled, "Join the Discussion." Clicking there opens the Open Learning Support website maintained by Utah State University which provides browsers and members with yet another forum through which to react to Connexions ${ }^{\circledR}$ modules and courses.

- The author level adds authoring and collaborating capabilities for registered members. Users customize existing materials, contribute new materials, and share meta-knowledge gained by using EAC resources. This level also allows members to collaborate online to coauthor EAC resources. Thus, the Toolkit provides an environment that promotes multidimensional, interdisciplinary collaboration in the development and refinement of EAC resources and best practices. These activities are supported by Connexions ${ }^{\circledR}$ workspaces, Creative Commons attribution licenses, module updating features, and a version history feature. First, workspaces are areas within the Connexions ${ }^{\circledR}$ environment in which authors come together to create modules and course materials. Access to workspaces is restricted to individuals who join a particular workgroup; collaborating authors keep materials confidential within the workspace until they judge them ready for publication in the Connexions ${ }^{\circledR}$ Content Commons. Second, Creative Commons makes available to authors an "attribution license" that balances the right of authors to receive acknowledgment with the need of the EAC community to build upon and use these materials. This copyright feature is automatically made available every time an author creates a new module in Connexions ${ }^{\circledR}$. Other default features prompt participants to decide on module authors, maintainers, copyright holders, etc. when the new module is created. Connexions ${ }^{\circledR}$ also supports continual improvement by permitting authors to check out modules for refining. Other members who are interested in modifying a module to fit a different pedagogical context can check it out and make a derived copy. Connexions ${ }^{\circledR}$ courseware integrates into the derived copy a default reference to the original module so that the original author's contribution is acknowledge while documenting the modifications made by the derived copy. Finally, the version history feature embedded in the module allows readers to track changes in the published module as well as identify derived copies that other users have made. These features facilitate the documentation of continual improvement required by various assessment strategies including those of ABET (Accreditation Board of Engineering and 
Technology) and AACSB (Association for the Advancement of Collegiate Schools of Business).

These levels (and the supporting Connexions ${ }^{\circledR}$ courseware platform) encourage the emergence of valuable editing and mentoring collaborations. Ethicists and BSE faculty working in the Toolkit interact to educate and mentor one another as well as collaborate throughout the conceptualization, editing, use, assessment, and refinement of EAC Modules. The next section will advance this description of the EAC Toolkit by outlining the Student and Instructor Module concepts.

\section{EAC Toolkit "Structure"}

Modules are the building blocks of skills and knowledge in EAC. By putting EAC in concrete form, they make possible structured ethics interventions in BSE classrooms. Modules employ EAC pedagogical best practices (cases, textbook exercises, frameworks, ethics codes) and compile pedagogical information and strategies. The EAC Toolkit concept makes use of two kinds of module, the Student Module (SM) and the Instructor Module (IM). Student Modules are ethics integration exercises developed specifically for integration into the BSE curriculum. They are created by interdisciplinary groups working within Connexions ${ }^{\circledR}$ workspaces and are, upon completion, published in the Connexions ${ }^{\circledR}$ Content Commons. Toolkit participants create modules from class handouts, short cases or scenarios, textbook exercises, and links to online resources.

SMs, by means of the Connexions $®$ features outlined above, draw these scattered resources together into networks or nodes of EAC knowledge. Figure A below pictures the constituent parts of a SM. It shows how the module consists of activities, information, and meta-data that are built around a "core" such as a scenario or problem with ethical implications.

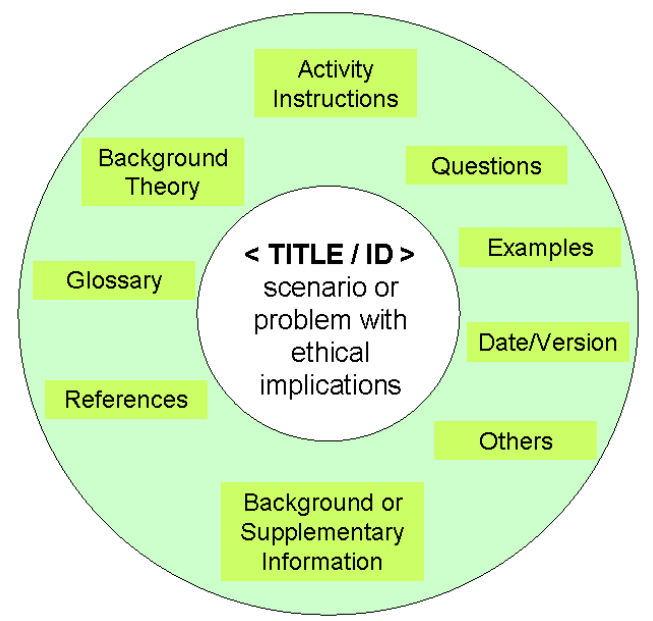

Figure A: EAC Student Module Structure

Toolkit developers have also designed an Instructor Module (IM) that gathers and disseminates the meta-knowledge relevant to developing and teaching a Student Module. In writing an IM, Toolkit authors collaborate to provide in-depth accounts of the corresponding SM's pedagogical 
content. These IM components provide, roughly speaking, a taxonomy of meta-knowledge categories responding to the needs of the EAC community. Because these needs are best met through collaborative, interdisciplinary action, the Toolkit creates the space for EAC community participants to contribute according to their expertise by "filling in" an IM template. Figure B below depicts the Instructor Module template. It provides a list of optional elements for development.

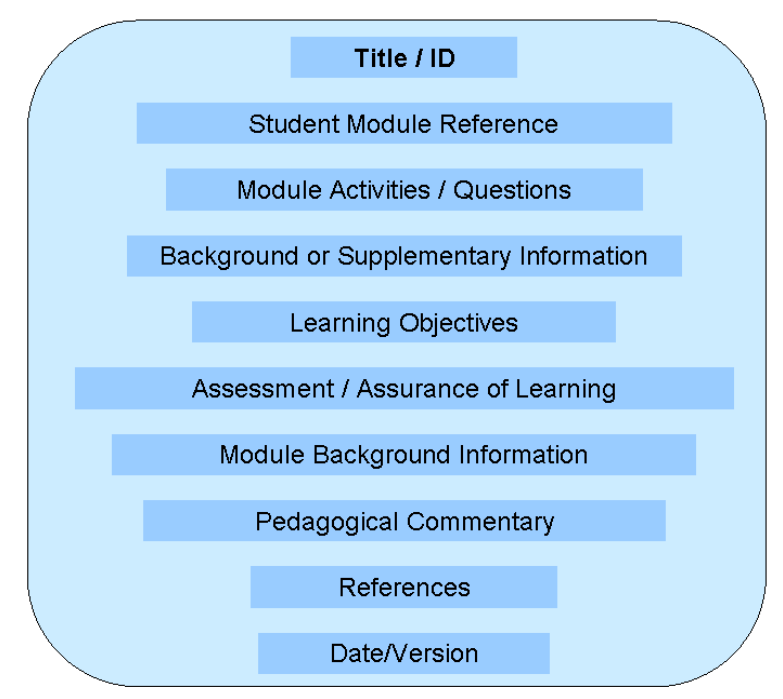

Figure B: EAC Instructor Module Structure

IM's link directly to SM's; usually the SM is embedded in the IM as a link. (See figure C below.) The IM supports the corresponding SM by outlining how others have used the module. It also provides new users with a forum through which they can (1) share their experiences with and insights about the module, (2) provide feedback to the SM's authors, and (3) disseminate the module adaptations they have made through the publication of derived copies. In short, the IM provides a template to collect meta-data that guides future module development. But it serves the more important objective of helping to shape positively the interactions between members of the EAC community.

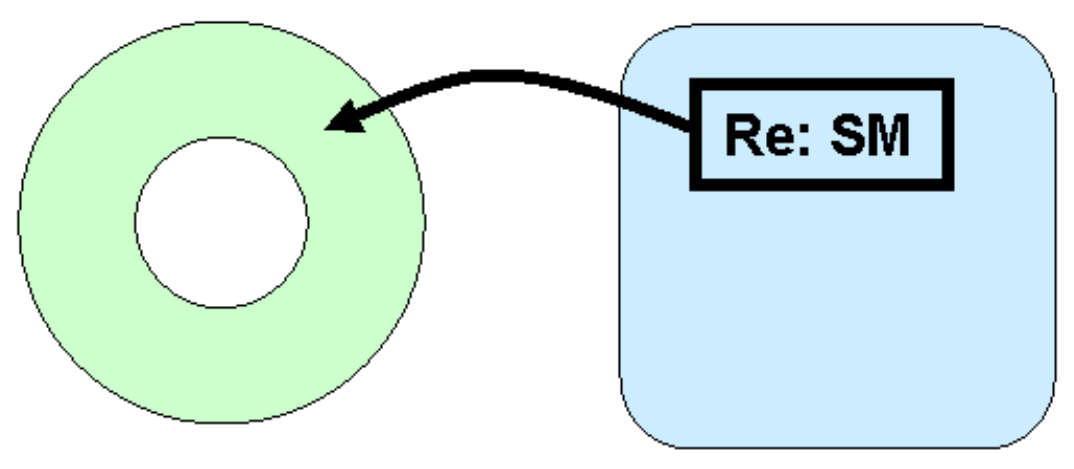

Student Module Instructor Module 
Figure C: Relationship between Student and Instructor Modules

\section{Toolkit Modules—Some Examples:}

To date, Toolkit project developers have published 56 modules and 7 courses (or collections) in the Connexions ${ }^{\circledR}$ Content Commons; most of these have been used in the classroom, assessed on the basis of these uses, and refined through module check outs or derived copies. This section examines two sample modules published in the Connexions ${ }^{\circledR}$ Content Commons: (1) Pirate Code for Engineering Ethics ${ }^{7}$ and (2) EAC Toolkit - Instructor Module: Pirate Code of Ethics. ${ }^{8}$

Sample Student Module-Pirate Code for Engineering Ethics

- Source: The movie series on the "Pirates of the Caribbean" suggested the idea of using the Pirate Credo as point of entry into the study of occupational and professional codes of ethics. The Pirate Credo itself provides a natural context in which the standard criticisms brought against professional and occupational codes arise. Students discuss the Pirate Credo to acquire an understanding of the basic characteristics and functions of codes. Then in small groups they write their own professional or occupational codes defending them against the critical scrutiny of their peers. Finally, they use this background experience with codes to encounter critically the dominant professional and occupational codes of their area of study. This process circumvents the primary objection to code-based pedagogy, namely, that it leads to indoctrination. ${ }^{9}$

- Development: This module evolved from its first form as a short PowerPoint presentation whose slides contained samples from the Pirate Credo to a full blown EAC unit published in the Connexions ${ }^{\circledR}$ Content Commons. Creative variations have been developed by other professors. For example a humanities professor at the University of Puerto Rico at Mayagüez (UPRM) uses a derived copy of this module to teach Machiavelli and Montaigne to students in Basic Humanities; students write their codes from the point of view of these Humanities figures.

- Publication: The Pirate Code for Engineering Ethics module was published in the Connexions ${ }^{\circledR}$ Content Commons on September 7, 2006. Since that date it has undergone nine revisions including the most recent (March 2, 2007) where the module summary was updated. This information, useful for documentation, can be accessed at the bottom of the module through the Version History feature. ${ }^{7}$ Moreover, this feature retains the previously published versions to allow a careful charting of the module's continual improvement.

\section{Sample Instructor Module-EAC Toolkit - Instructor Module: Pirate Code of Ethics.}

- Source. This IM corresponds to the SM described just above on the Pirate Code of Ethics. It links directly to the SM and represents a continually evolving attempt to collect the meta-data generated by teaching, disseminating, and assessing it.

- Assessment and assurance of learning materials. The Pirate Code IM provides assessment forms that students can fill out after completing the SM. It also lists different pedagogical goals to help would-be users assess their experience with the module. The Pirate Code IM includes suggestions on how to assess the module for accreditation efforts such as ABET and 
AACSB, including an EAC Matrix that allows users to view the module's contribution to an overall ethics integration program. In short, the IM template provides materials among which interested users can pick and choose for their own specific needs and contexts. It invites users to provide feedback on the SM and to develop derived copies that they can share with the EAC community.

- Pedagogical strategies. The Pirate Code IM outlines the pedagogical strategies (informal writing, cooperative learning, general class discussion, knowledge elicitation) employed by the Pirate Code SM. It also describes the skills and background knowledge students need to begin the SM.

- Pedagogical commentary. This section draws upon the experience of the author in teaching the SM. It consists of practical suggestions for discussing the Pirate Credo with students, tips for anticipating and solving problems encountered by students in writing their own codes, and suggestions on how to help students critically approach existing practical and professional ethics codes. The IM emphasizes the danger of indoctrination in teaching codes of ethics and suggests ways of avoiding this pedagogical pitfall.

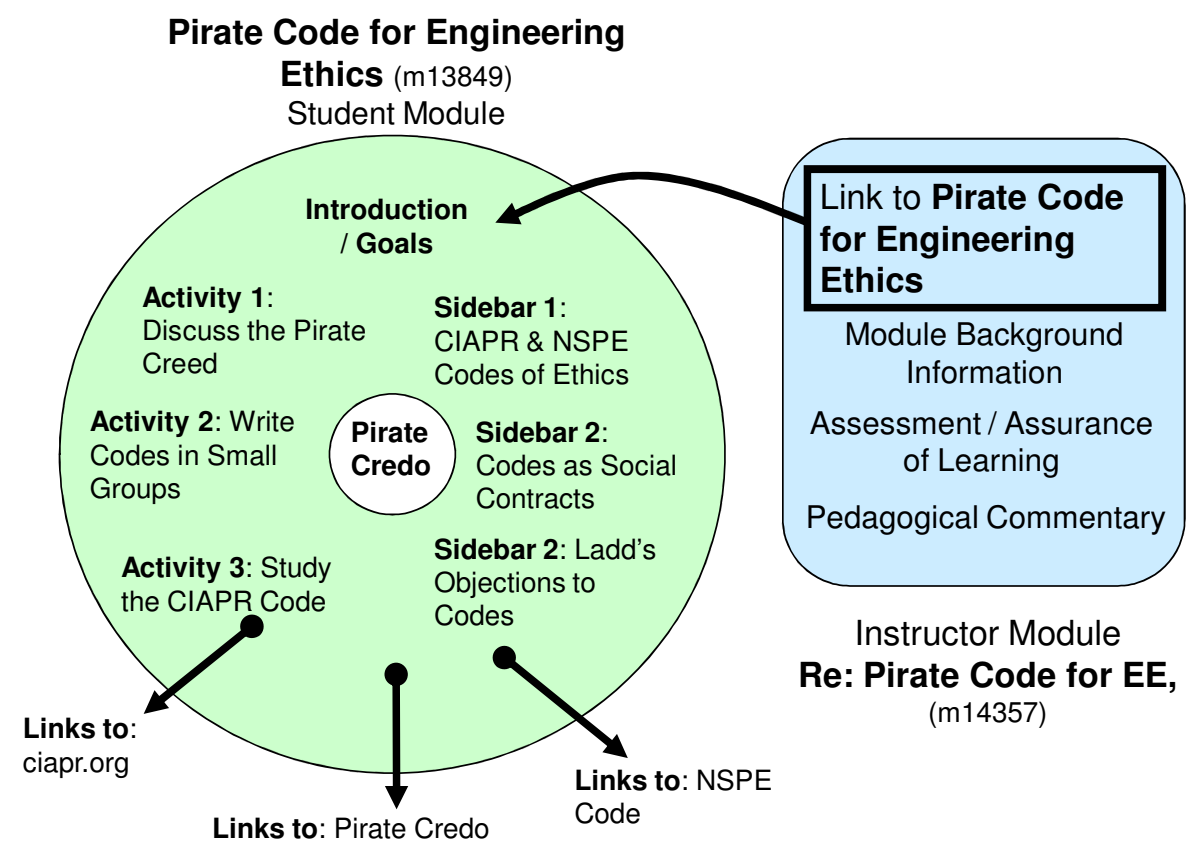

Figure D: Pirate Code for Engineering Ethics-SM and IM

\section{Toolkit Workshop}

The EAC Toolkit has been designed to complement and complete the EAC faculty development workshops that have been held at the University of Puerto Rico at Mayagüez (UPRM) since 2001. These workshops have been successful in committing BSE faculty to EAC, in giving them the confidence and skill needed to carry out ethics integration projects in their classes, and in developing new cases and classroom exercises in EAC. ${ }^{1}$ This section reports on how the faculty 
development workshop format used at UPRM has been expanded to include a Toolkit component.

The workshop format has been designed to realize four objectives: (1) to incorporate the EAC Hybrid approach as a viable strategy for integrating ethics into the professional and occupational curricula, (2) to utilize the module approach as a tool to integrate ethics into the curricula, (3) to give and receive feedback in the context of open source modules, and (4) to appreciate the importance of establishing continuity (a community) as part of the EAC Hybrid approach. In Table 1, the workshop activities have been correlated with these objectives.

Day-long workshops were carried out on May 9, 2007 with faculty from UX's College of Business Administration and on September 17 for UPRM's faculty from engineering, nursing, business administration, agriculture, and the sciences. While Table 1 provides a detailed summary of the activities, these can be encapsulated into the following:

- Introduction: Each workshop introduced participants to concepts of ethics across the curriculum and the EAC Toolkit. Demos helped participants gain insight into the look and feel of different aspects of the Connexions ${ }^{\circledR}$ courseware environment.

- EAC Module Presentations: Presentations on past successful ethics integration modules helped familiarize participants with EAC best practices and the Toolkit module concept. Past experience has shown that modeling EAC best practices gives participants the confidence that they can develop and implement their own. These two workshops reinforced that experience.

- Developing EAC interventions: Participants took advantage of workshop time to develop their own modules in EAC. They prepared these in small groups. Then each group presented its module ideas to the rest of the participants for comment and feedback.

The original plan was for each workshop to conclude with preparing SM drafts for publication in Connexions. ${ }^{10}$ But experience (and assessment) showed that this was a bit too ambitious for a day-long workshop. Consequently, two further mini-workshops (2-3 hours) were planned: the first took place November 2, 2007. Thus, the workshop component of the EAC Toolkit can best be seen as a workshop series that takes one year to complete:

1. In the day-long first workshop participants learn about EAC, the Toolkit, and develop (with peer feedback) ideas for their own SMs.

2. In the first mini-workshop, participants upload a complete module draft into their Connexions ${ }^{\circledR}$ workspace.

3. During the following semester, each participant tries out and assesses his or her EAC Student Module.

4. Finally, in the second mini-workshop, participants report on their efforts and prepare an IM to correspond with their SM.

Table 1 enumerates the activities of the workshop held September 17, 2007 before an interdisciplinary group of UPRM's faculty. These activities have been correlated with workshop goals. Table 2 summarizes assessment results for two EAC Toolkit faculty development workshops, one held May 9, 2007 and the other held September $17^{\text {th }}$. The assessment results reported here represent preliminary findings which will be supplemented by documenting the 
SMs and IMs published, and the assessments of the effectiveness of these modules in promoting EAC objectives and outcomes in the classroom. During the workshops held May 9 and September 17, participant feedback that came from face to face interactions between workshop leaders and workshop participants gave form to the emergence of the yearly workshop series, the day-long introductory activity and the two mini follow up workshops.

\section{WORKSHOP AGENDA FOR SEPTEMBER 17, 2007}

\begin{tabular}{|l|l|}
\hline Activity & Objective \\
\hline Brief Review of EAC & Incorporating EAC \\
\hline EAC Student Module Promoting Ethical Awareness & Utilizing modular approach \\
\hline EAC Instructor Module: Sharing Best Practices & Utilizing modular approach \\
\hline Customizing a Module & Utilizing modular approach \\
\hline Break & \\
\hline Sources and Ideas for EAC Exercises & Incorporating EAC \\
\hline Structuring an EAC Exercise & Incorporating EAC \\
\hline Developing your own EAC exercise & Incorporating EAC \\
\hline Lunch & \\
\hline Team Presentations & Receive Feedback \\
\hline How to post and share your EAC module & Appreciate Community \\
\hline Document and share your EAC expertise & Receive Feedback / Appreciate Community \\
\hline Conclusion and Evaluation & \\
\hline
\end{tabular}

Table 1: Enhanced EAC Workshop Format

\section{WORKSHOP ASSESSMENT RESULTS}

\begin{tabular}{|l|l|l|}
\hline Questions & May & Sept \\
\hline The objectives of the session were clearly stated. & 4.44 & 4.65 \\
\hline The objectives proposed were met. & 4.56 & 4.30 \\
\hline The activities presented were well organized. & 4.56 & 4.15 \\
\hline The presenters were prepared. & 4.67 & 4.85 \\
\hline The activities provided opportunities for participation. & 4.78 & 4.85 \\
\hline Time was managed appropriately. & 4.00 & 3.68 \\
\hline The topics presented were of relevance to my present work. & 4.38 & 4.65 \\
\hline My expectations were satisfied. & 4.13 & 4.40 \\
\hline There was a sense of closure at the end of the activities and retreat. & 4.11 & 4.35 \\
\hline I will be able to put into practice the ideas presented. & 3.88 & 4.55 \\
\hline This retreat was a valuable learning experience. & 4.13 & 4.50 \\
\hline The materials provided were useful. & 4.67 & 4.60 \\
\hline
\end{tabular}

Table 2: Workshop Assessment

\section{Conclusion}

This paper has discussed a new project in EAC teaching and pedagogy, the EAC Toolkit, by placing it in the context of implementing EAC in the BSE curriculum, by describing the components of the Toolkit itself as it interacts with the courseware provided by Connexions ${ }^{\circledR}$, and by tracing the development of two modules that have emerged during the initial stages of the 
implementation of the Toolkit. A workshop series planned for spring and fall 2007 has been outlined in terms of its activities and their respective objectives. This paper represents a midproject report and will be followed with an update summarizing the assessment of the workshops and the further development of Toolkit modules and resources. The authors invite readers to view sample Toolkit modules online at the Connexions ${ }^{\circledR}$ Content Commons, http://cnx.org. Modules can also be found through an author search under the names of Frey or Cruz. Those interested in joining the Toolkit EAC community can register with Connexions ${ }^{\circledR}$ and participate in the feedback and authoring features they provide. Readers can contact this paper's authors if they wish to be added to Toolkit workgroups.

\section{Acknowledgement}

The authors wish to acknowledge the National Science Foundation for supporting and funding this project whose title is "Collaborative Development of Ethics Across the Curriculum Resources and Sharing of Best Practices," NSF SES 0551779.

\section{Bibliography}

[1] José A. Cruz-Cruz, William J. Frey (2003) An Effective Strategy for Integrating Ethics Across the Curriculum in Engineering: An ABET 2000 Challenge, Science and Engineering Ethics, 9(4): 543-568.

[2] G. Henry, R. G. Baraniuk, C. Kelty (2003) The Connexions Project: Promoting Open Sharing of Knowledge for Education," Syllabus2003 Conference, July.

[3] G. Henry, R. G. Baraniuk (2004) Papers and Talks - Peer To Peer Collaboration Using Connexions, American Society for Engineering Education Annual Conference \& Exposition, Salt Lake City, Utah, June.

[4] R. G. Baraniuk, G. Henry, B. Hendricks (2004) Peer to Peer Collaboration with Connexions, EDUCAUSE 2004 Annual Conference, Denver, Colorado, October.

[5] http://www.cnx.org.

[6] http://cnx.org/lenses/eactoolkit/eactoolkit.

[7] http://cnx.org/content/m13849/latest.

[8] http://cnx.org/content/m14357/latest.

[9] David R. Haws (2004) The Importance of Meta-Ethics in Engineering Education, Science and Engineering Ethics 10(2): 204-210.

[10] José A. Cruz-Cruz, William J. Frey (2007) Work in Progress - The Ethics Across the Curriculum Toolkit: An Online Environment for Ethics Resources, Proceedings, $37^{\text {th }}$ ASEE/IEEE Frontiers in Education Conference,

Milwaukee, WS, October 13, 2007: S4H-9. 